\title{
Comments on "Estimating the Strength of Jointed Rock Masses" by Lianyang Zhang
}

\author{
Ergin Arığlu • Gözde Kurt · Sanem Kayalı
}

Published online: 7 June 2011

(C) Springer-Verlag 2011

\section{Introduction}

Zhang, in his article written in 2010 is estimating the strength of jointed rock masses. He deals with the estimation of the uniaxial compressive strength of jointed rock masses $\left(\sigma_{\mathrm{cm}}\right)$ and proposes a new empirical expression based on rock quality designation (RQD). The interested participants read the article with great interest and scrutiny. As the author states, 'the estimation of the uniaxial compressive strength of rock masses is an important and challenging issue in the rock engineering field'. Despite the several limitations, RQD is the only parameter available for characterising the degree of jointing (block volume, joint spacing). Hence the discussers appreciate the authors' comprehensive investigation to provide a new $\left(\sigma_{\mathrm{cm}} / \sigma_{\mathrm{c}}\right)$ versus (RQD) relationship. Some findings derived from the comparisons based on different approaches are very important and are worthy of further discussion to enhance our understanding of the strength of jointed rock masses.

\section{Comments on New Relation Between Uniaxial Compressive Strength and RQD}

The parameters affecting the strength of rock masses are illustrated in Fig. 1 (modified from Palmström 1996). It is immediately apparent that the RQD value only covers the density of the joints, i.e. the block size. The weathering degree may be partly expressed by means of RQD. In other

E. Arıoğlu $(\bowtie) \cdot$ G. Kurt $\cdot$ S. Kayalı

Yap1 Merkezi R\&D Department, Hacı Resit Pasa Sok. No:7,

Camlica, 34676 Istanbul, Turkey

e-mail: ergin.arioglu@ym.com.tr words, the majority of the parameters are not taken into account for or a balanced view in this article.

\subsection{Comparison with Joint Factor Approach}

In the approach proposed by Ramamurthy (1993); Ramamurthy and Arora (1994); Ramamurthy (2001), the ratio of the uniaxial compressive strength of a jointed rock mass $\left(\sigma_{\mathrm{cm}}\right)$ to the uniaxial compressive strength of intact rock $\left(\sigma_{\mathrm{ci}}\right)$ is related to a joint factor $\left(J_{\mathrm{f}}\right)$ (Fig. 2). This factor takes into account joint frequency $\left(J_{\mathrm{n}}\right)$, i. e. the RQD in the direction of loading/major principal stress inclination of a sliding joint or joint set $(\beta)^{\circ}$ and the strength along the sliding joint. The values of $n$ are found to be almost independent of the joint frequency $\left(J_{\mathrm{n}}\right)$ for an inclination of the joint set.

For a given joint strength $(r)$ the strength reduction ratio $\left(\sigma_{\mathrm{cm}} / \sigma_{\mathrm{ci}}\right)$ at any inclination of joint set $\left(\beta^{\circ}\right)$ can be estimated. In comparison, the joint strength $(r)$ corresponding to joint gauge material clayey sand material was taken as $\operatorname{tg} \phi_{\mathrm{j}}=\operatorname{tg} 30^{\circ}=0.58$ (see Fig. 2).

The joint frequency $\left(J_{\mathrm{n}}\right)$ can be expressed in terms of RQD using the following formula given by Priest and Hudson (1976).

$\mathrm{RQD}=100\left(0.1 J_{\mathrm{n}}+1\right) \exp \left(-0.1 J_{\mathrm{n}}\right)$

The joint inclination parameter $(n)$ considering anisotropy can be approximated using simple regression analysis as follows:

$n=0.931 \exp \left(-0.098 \beta^{\circ}\right) \quad 0<\beta^{\circ} \leq 30^{\circ}$

$n=3.26 .10^{-6} \beta^{2,85} \quad 30<\beta^{\circ}<90^{\circ} F$

Furthermore, the joint strength factor $r$ for unfilled joints and joints filled by gauge materials can be provided as 


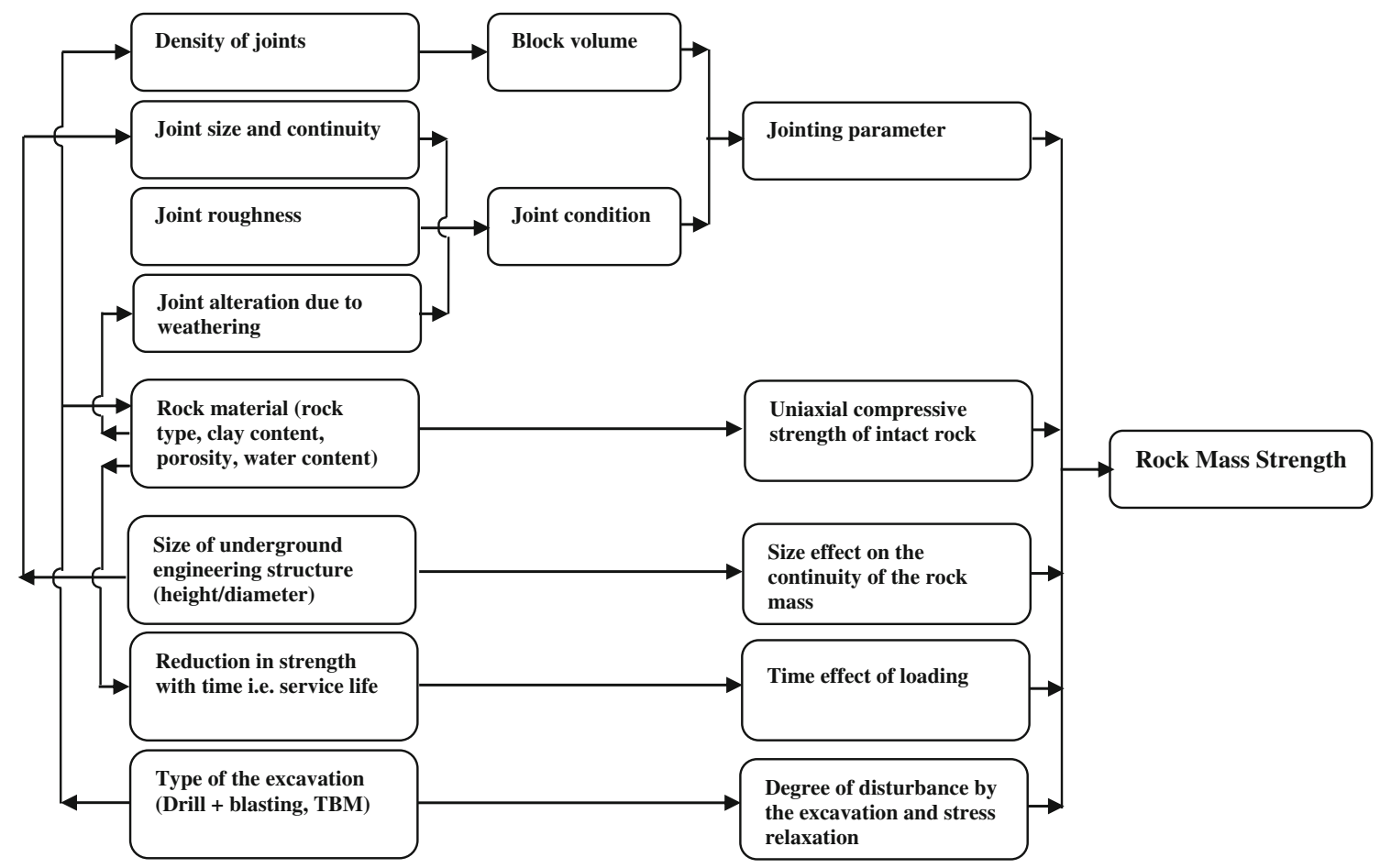

Fig. 1 Parameters affecting the uniaxial compressive strength of rock mass

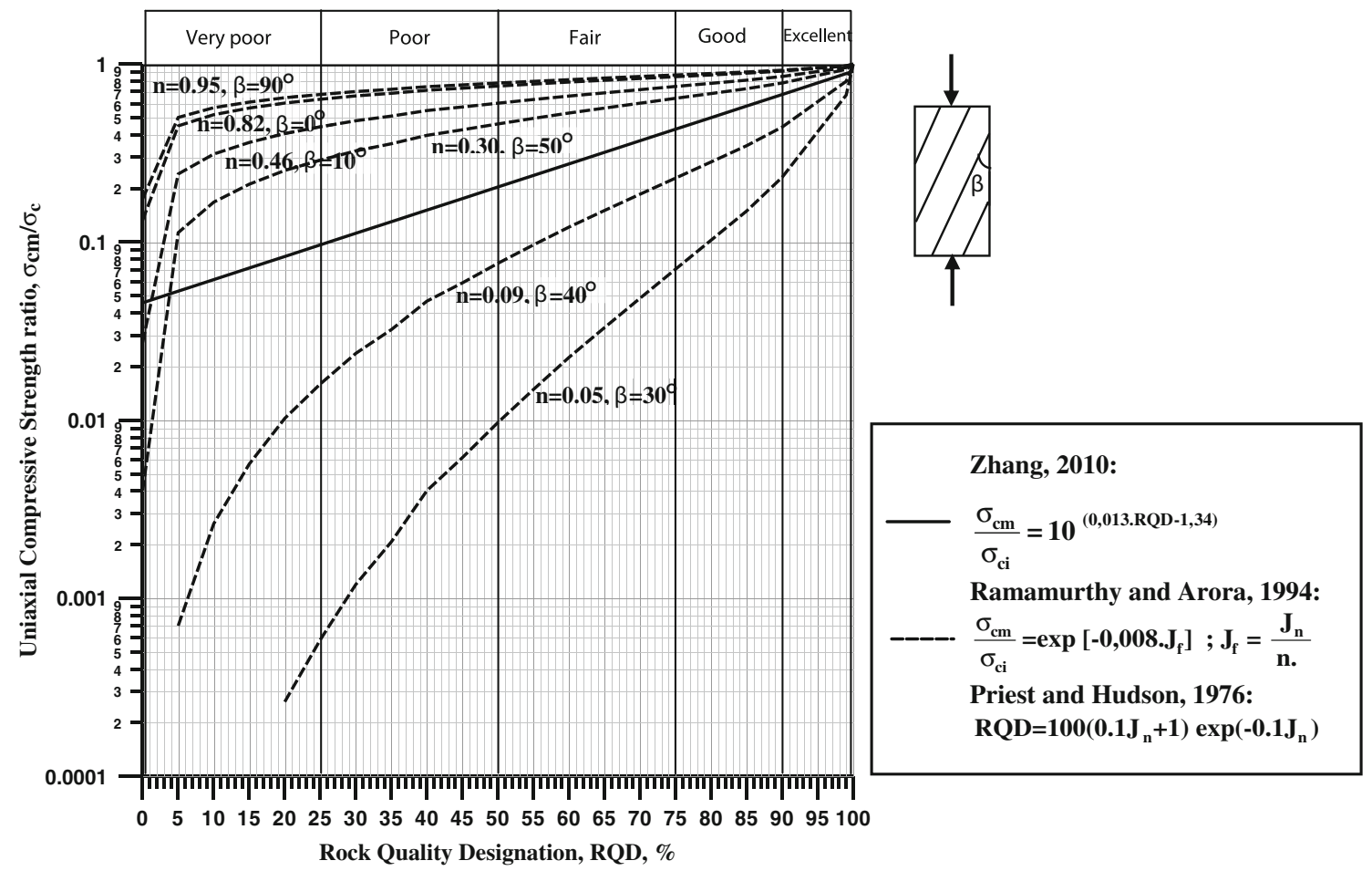

Fig. 2 Here we approach the relationship between uniaxial compressive strength ratio $\left(\sigma_{\mathrm{cm}} / \sigma_{\mathrm{ci}}\right)$ with rock quality designation, RQD $\left(\sigma_{\mathrm{cm}}, \sigma_{\mathrm{ci}}=\right.$ the uniaxial compressive strength of rock mass and intact rock, respectively, $J_{\mathrm{f}}=$ the joint factor. Its value stands for the quality reduction/weakness in the intact rock, $J_{\mathrm{n}}=$ the joint frequency, i.e. number of joints per meter, joint $/ \mathrm{m}, n=$ an inclination parameter depending on the orientation of the joint, $\beta, r=$ the joint strength parameter depending on the joint condition-whether clean and rough or filled-up joints, thickness of joint and joint alteration owing to weathering-,$\phi_{\mathrm{j}}=$ for gouge filled joints the friction angle of joint. In analysis, the $r$ value was assumed to be $\phi_{\mathrm{j}}=30^{\circ}$ (clayey sand), i.e. $r=\operatorname{tg} \phi_{\mathrm{j}}=\operatorname{tg} 30^{\circ} \approx 0.58$ ) 
$r=0.182 \ln \sigma_{c}+0.131 \quad 5 \mathrm{MPa}<\sigma_{c}<100 \mathrm{MPa}$

$r=0.013 \phi_{\mathrm{j}}^{1.124}$

$10^{\circ}$ (clay content) $75 \%<\beta<45^{\circ}$ (gravelly sand)

$\left(\sigma_{\mathrm{c}}=\right.$ Joint wall compressive strength, $\mathrm{MPa}, \phi_{\mathrm{j}}=$

Internal friction angle of gauge material, ${ }^{\circ}$ ).

From Fig. 2 the following findings can be derived:

- For the given $n$ and $r$ values the $\left(\sigma_{\mathrm{cm}} / \sigma_{\mathrm{ci}}\right)$ ratio based on Ramamurthy and Arora 1994 significantly increases with an enhancement in RQD. The same trend appears also in Zhang's approach.

- In the case of a given RQD value and joint strength $(r)$, the inclination parameter depending on the inclination of the joint plane with respect to the major principal stress plays an important role in the magnitude of its strength.

\subsection{Comparison with Rock Mass Index}

A more comprehensive approach to estimate the uniaxial compressive strength of jointed rock masses $\left(\sigma_{\mathrm{cm}}\right)$ has been proposed by Palmström 1995 and 1996. As can be seen from Fig. 3, the $\sigma_{\mathrm{cm}}$ is based on the reduced intact rock strength $\left(\sigma_{\mathrm{ci}}\right)$ induced by jointing factor $(\mathrm{JP})$ related to the block size $\left(D_{\mathrm{b}}\right)$ and the condition of its faces (JC). The magnitude of JP fluctuates close to 0 for crushed rock masses-particulate geomaterials-to 1 for intact rock. The influence of JP has been determined using calibrations from in situ/laboratory test results.

The joint condition factor is provided as JC $=\mathrm{JL}(\mathrm{JR} /$ $\mathrm{JA}$ ), in which JL, JR and JA are parameters for joint length and continuity, joint wall roughness and the joint surface alteration owing to weathering, respectively. Detailed information on the values of JL, JR and JA can be obtained from relevant references.

For a given block shape $(\beta)$ the block volume $\left(V_{\mathrm{b}}\right)$ can be correlated with the volumetric joint count (joints $/ \mathrm{m}^{3}$ rock mass), i.e. RQD. Then, the $\sigma_{\mathrm{cm}}$ can be expressed in terms of RQD as given below:

$\frac{\sigma_{\mathrm{cm}}}{\sigma_{\mathrm{ci}}}=0.2(\mathrm{JC})^{0.5}\left[\beta(44-0.4 \mathrm{RQD})^{-3}\right]^{0.37(\mathrm{JC})^{-0.2}} \mathrm{IL}$

In common block shape (for $\beta=36$ ), the joint conditions (for $\mathrm{JC}=1.75$ slightly undulating, rough joints) and common interlocking $\mathrm{IL}=1$ (Palmström and Stille 2010) the above equation becomes:

$\frac{\sigma_{\mathrm{cm}}}{\sigma_{\mathrm{ci}}} \approx 0.87(44-0.4 \mathrm{RQD})^{-1}$

Figure 3 displays a comparison of the author's expression with $\left(\sigma_{\mathrm{cm}} / \sigma_{\mathrm{ci}}\right)$ ratio proposed by Palmström (1995), based on the entire range $0<\mathrm{RQD} \leq 100 \%$. As can be noticed the results derived from the studied approaches appear extremely different. This difference can be attributed to the fact that the approach based on $\left(\sigma_{\mathrm{cm}} / \sigma_{\mathrm{ci}}\right)$ versus RQD solely accounts for the block size $V_{\mathrm{b}}$. Referring to a complex rock mass structure, various parameters such as the joint conditions, and the state of interlocking of the rock mass structure play important roles in the magnitude of the rock mass strength. If these parameters are combined in an appropriate mechanical model they can provide a reasonable rock mass strength.

From Fig. 3 it can be concluded that the maximum rock mass strength corresponding to massive homogenous hard rock mass, i.e. $\mathrm{RQD}>80 \%$ and interlocking factor $\mathrm{IL}=1$ amounts to

$\sigma_{\mathrm{cm}} \approx 0.5 \sigma_{\mathrm{ci}} \mathrm{IL} \approx 0.5 \sigma_{\mathrm{ci}}$

which concur with the results reported by Arığlu et al. 1999 and Yoshinaka et al. (2008).

\subsection{The Effect of Tunnel Span on the Strength}

Various empirical approaches for estimating the uniaxial compressive strength of rock mass do not include the effect of tunnel span. Whereas, for a given block diameter $\left(D_{\mathrm{b}}\right)$, i.e. joints spacing $(S)$ the increase in excavation diameter/ span $\left(D_{\mathrm{e}}\right)$ has an influence on "continuity of rock mass" $\left(\mathrm{CF}=D_{\mathrm{b}} / D\right)$ which defines the principle types of mechanical behaviour depending on the magnitude of stress state (Palmström and Stille 2010).

Perhaps, the effect of $\left(D_{\mathrm{e}} / D_{\mathrm{d}}\right)$ on the in situ strength of rock mass $\left(\sigma_{\mathrm{cm}}\right)$ was first described by Former Soviet mining engineers (Amusin 1998):

$\sigma_{\mathrm{cm}}=\sigma_{\mathrm{ci}} f_{\mathrm{j}} f_{\mathrm{d}} f_{\mathrm{a}} f_{\mathrm{t}}$

in which $f_{\mathrm{j}}$ takes into consideration the scale effect due to jointing, its value can be calculated from the following empirical expression:

$f_{j}=\frac{1}{1+0.7 \frac{\ln D_{e}}{S}}$

$S$ is an average spacing between the joint sets. Its value can be written in the terms of block volume $\left(V_{\mathrm{b}}\right)$ or block diameter $\left(D_{\mathrm{b}}\right)$ using the following equations: $S \approx D_{\mathrm{b}} \approx$ $\left(V_{\mathrm{b}}\right)^{0.333}$ (Palmström 1995). $f_{\mathrm{d}}$ is the correction factor covering the effect of direction of the excavation relative to the strike direction $f_{\mathrm{d}}=0.6+2 \times 10^{-3} \sigma_{\mathrm{ci}}, f_{\alpha}$ is a correction factor taking into account the effect of the reduction in virgin vertical stress. $f_{\alpha}=\exp \left(\alpha H_{\mathrm{s}} / 400\right)$. $\alpha$ is the dip angle of the strata in degree, $H_{\mathrm{s}}=\frac{\gamma H}{f_{j} \sigma_{\mathrm{ci}}} ; \gamma$ is unit weight of rock mass, $\mathrm{MN} / \mathrm{m}^{3}, H$ is the depth of the excavation below the surface, in meters, $\sigma_{\mathrm{ci}}$ is the uniaxial compressive strength of intact rock, MPa. Factor $f_{\mathrm{t}}$ is the reduction in strength with time. This factor is provided by 


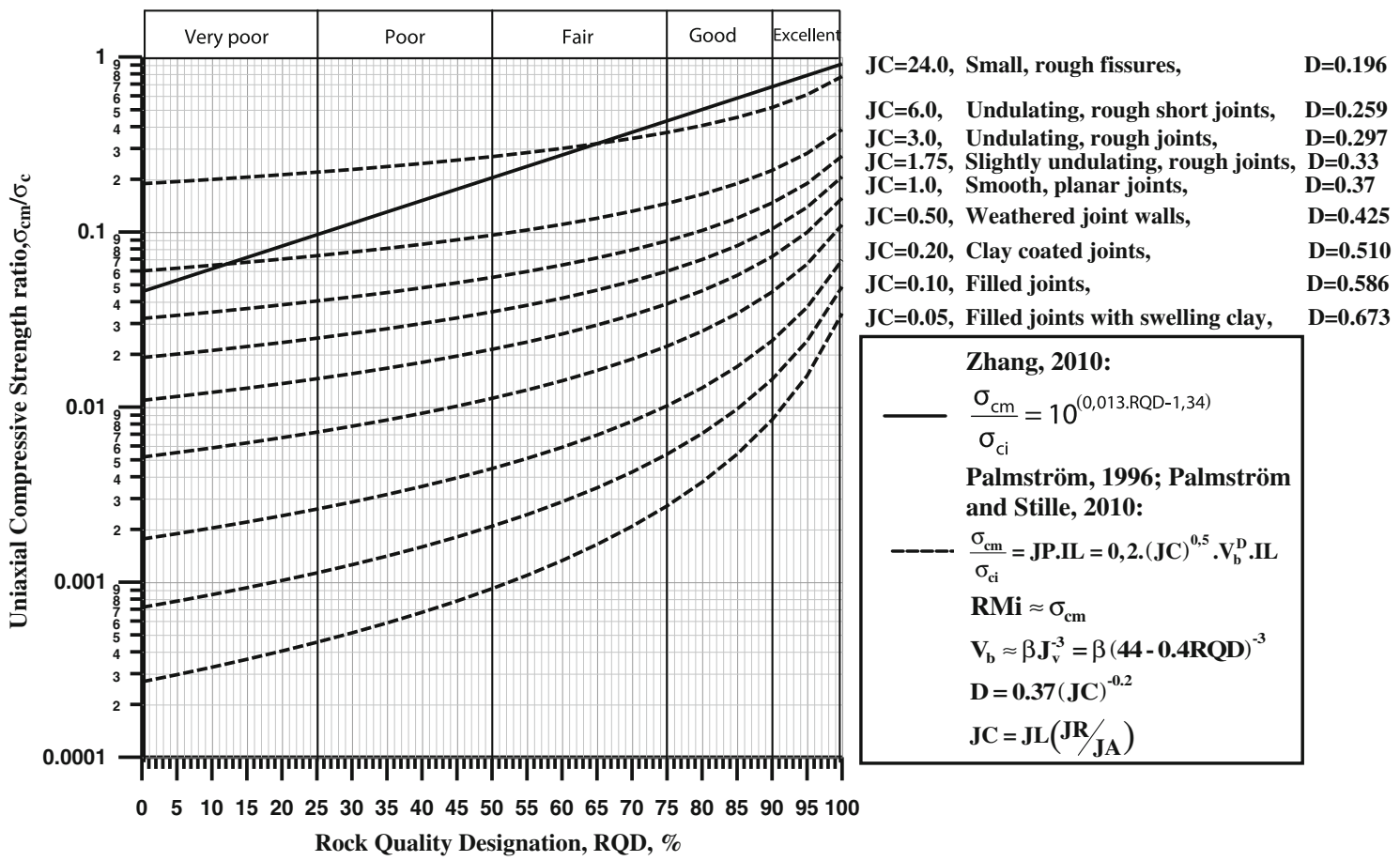

Fig. 3 For two approaches relationship between uniaxial compressive strength ratio with rock quality designation, RQD $\left(\sigma_{\mathrm{cm}}\right.$, $\left.\sigma_{\mathrm{ci}}\right)=$ the uniaxial compressive strength of rock mass and intact rock, respectively, $\mathrm{RMi}=$ the rock mass index, $\mathrm{JP}=$ the jointing parameter. The value of JP changes from almost 0 for crushed rocks to 1 for intact rock, IL = interlocking factor taking account for compactness of rock mass. Its value varies from 1.3 to 0.5 . For

$f_{\mathrm{t}}=f_{\infty}+\left(1-f_{\infty}\right) \exp \left(-\alpha_{1} t\right) \approx 0.7$

Where $f_{\infty}=0.6-0.9$ is the relative limit of long-term strength in dimensionless, $\alpha_{1}$ is a factor describing a rate of strength ratio. Its value can be determined from a back analysis of changing displacements over time. In the absence of the data the value of $\alpha_{1}$ can be taken as 0.05 (1/day), $t$ is time in days. This factor $\left(f_{t}\right)$ will be also discussed in the following section.

Goel et al. (1995) proposed an empirical expression for the estimation of the rock mass strength, on the basis of back analysis of data gathered from several tunnels in the Himalayan region (Singh and Goel 2006):

$\sigma_{\mathrm{cm}}=5.5 \gamma N^{0.333} B^{-0.1} \quad \mathrm{MPa}(0.01<N<700)$

$\sigma_{\mathrm{cm}} \approx 14.85\left(\frac{\mathrm{RQD} J_{\mathrm{r}} J_{\mathrm{w}}}{J_{\mathrm{n}} J_{\mathrm{a}}}\right)^{0.333} B^{-0.1} \quad$ MPA

Where $\gamma=$ unit weight of rock mass, $\mathrm{t} / \mathrm{m}^{3}, \gamma \approx 2.7 \mathrm{t} / \mathrm{m}^{3}$, $N=$ rock mass number, i.e. stress-free $Q$ factor soon after the tunnel excavation, RQD. Where RQD is reported or measured as $10 \%$ (including 0 ), a nominal value of 10 is used to estimate $N$ value. $J_{\mathrm{n}}=$ rating of joint set number, $J_{\mathrm{r}}, J_{\mathrm{a}}=$ for the critical orientation of the joint sets or filled example disturbed rock mass $\mathrm{IL}=0.8, \mathrm{JC}=$ the joint condition factor, which is a combined parameter for the joint size JL, joint roughness, JR and joint weathering/alteration factor, JA. Most commonly condition factor $\mathrm{JC}=1-2, V_{\mathrm{b}}=$ the block volume, $\mathrm{m}^{3}$, delineated by joints, $\beta=$ the block shape factor. For common block shape $\beta=36, J_{\mathrm{v}}=$ the volumetric joint count, joints $/ \mathrm{m}^{3}, D=$ a constant depending upon the JC value)

joints ratings of roughness and joint alteration, respectively. Its ratio can be approximated as the actual peak sliding angle of friction $\left(\phi_{\mathrm{p}}\right)$ along the clay coated joints, i.e. $\phi_{\mathrm{p}}=\operatorname{tg}^{-1}\left(J_{\mathrm{r}} / J_{\mathrm{a}}\right) . \quad J_{\mathrm{w}}=$ the parameter is a measure of water pressure. For dry condition or minor water inflow, i.e. $5 \mathrm{l} / \mathrm{min}$ locally $J_{\mathrm{w}}=1, B=$ tunnel span, $\mathrm{m}$.

The discussers may write the above mentioned expression as follows:

$\sigma_{\mathrm{cm}} \approx 14.85\left(\frac{\mathrm{RQD}}{J_{\mathrm{n}}} \operatorname{tg} \phi\right)^{0.333} B^{-0.1} \mathrm{MPa}$

$\left[\phi=\right.$ internal friction angle of rock mass. $\operatorname{tg} \phi=\frac{J_{\mathrm{r}}}{J_{\mathrm{a}}} J_{\mathrm{w}}$ (Barton 2007)]. For instance, typical values $J_{\mathrm{n}}=9$-three joint sets-, and $\phi \approx 30^{\circ}$ the above expression can be written

$\sigma_{\mathrm{cm}} \approx 6(\mathrm{RQD})^{0.333} B^{-0.1} \mathrm{MPa}$

Assuming $B=4$ and $12 \mathrm{~m}$ tunnel span, and mean RQD value $(\mathrm{RQD}=50 \%)$ the uniaxial compressive strength of rock mass may be predicted as around 19 and $17 \mathrm{MPa}$, respectively. The reduction ratio due to an enhance in span amounts to $10 \%$. 


\subsection{The Effect of Disturbance due to Excavation Type}

The effect of disturbance caused by excavation on the rock mass strength is an important issue and its magnitude is illustrated in Fig. 4 using the modified Hoek-Brown nonlinear failure criteria (Hoek et al. 2002). As can be noted, for the same GSI value the increased disturbance gives rise to a significant reduction in the rock mass strength. Referring to Alber (2000), there is a correlation between the RMR values derived from TBM tunnels and drill-andblast tunnels:

$\mathrm{RMR}_{\mathrm{TBM}}=0.8 \mathrm{RMR}_{\mathrm{D} \& \mathrm{~B}}+20$

In brief, for the TBM tunnels the rock mass strength is expected to be higher due to non-disturbance.

\subsection{The Effect of Loading Time}

A critical issue is that the rock mass strength estimation should include the long-term time-dependent behaviour of the rock mass surrounding the underground structure. This subject has been studied extensively in rock engineering literature. As the rheological models require the data (the viscosity coefficients and shear moduli) derived from special laboratory investigations, in engineering practice a variety of approaches have been proposed to some extent. Some of them have been defined using empirical methods in many underground coal mines. For instance, the longterm strength is provided as a certain portion of the shortterm strength (Unrug 1983; Birön and Arıoğlu 1983; Arıoğlu 1995; Amusin 1998; Hoek 2009). According to Hoek and Guevara 2009, the long-term rock mass strength is obtained on estimate of $(\mathrm{GSI})_{\mathrm{t}} \approx 0.5(\mathrm{GSI})_{\mathrm{d}}$. In which $(\mathrm{GSI})_{\mathrm{t}},(\mathrm{GSI})_{\mathrm{d}}$ are the long-term GSI values due to creep, progressively increasing plastic zone surrounding the tunnel and the design GSI based on short-term observations of freshly exposed rock mass in the tunnel, respectively. For example $(\mathrm{GSI})_{\mathrm{d}}=60$ and $D=0$ the long-term ratio $\left(\sigma_{\mathrm{cm}} / \sigma_{\mathrm{ci}}\right)$ can be predicted to be around 0.018 corresponding to $(\mathrm{GSI})_{\mathrm{t}}=30$. In other words, the $\left(\sigma_{\mathrm{cm}, \mathrm{t}} / \sigma_{\mathrm{cm}, \mathrm{d}}\right)$ ratio can be determined as $\left(\frac{0.018}{0.10}=0.18\right)$. This ratio may take into account for the changes in physical and chemical properties of unweathered rocks, resulting from only weathering process. As for the long-term uniaxial compressive strength of intact rock, $\sigma_{\mathrm{ci}}$, of course, its magnitude varies, in accordance with several factors such as the rock type, the structural defects on micro scale, humidity of environment, the applied stress level and loading rate, etc.

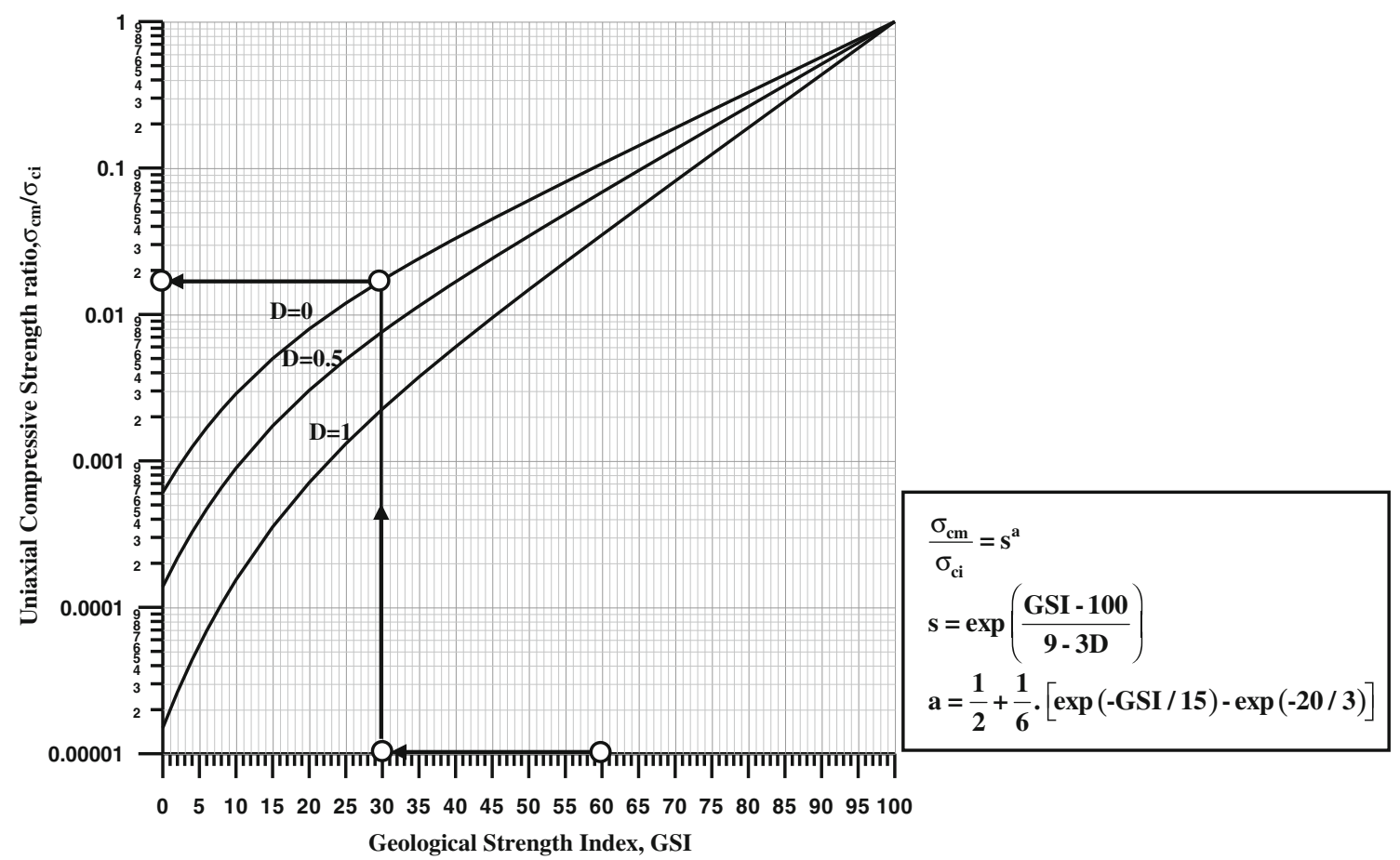

Fig. 4 Relationship between $\left(\sigma_{\mathrm{cm}} / \sigma_{\mathrm{ci}}\right)$ ratio and the Geological Strength Index (GSI) based on Hoek et al. 2002, with respect to a factor $(D)$ depending on the degree of disturbance owing to blast damage and stress relaxation $(D=0$ for undisturbed rock mass, i.e.

TBM excavation, $D=1$ for very disturbed rock masses, i.e. poor blasting practice, $s, a=$ the material constants depending on the GSI value) 


\section{Conclusions}

The following conclusions can be derived:

- On the basis of comparisons in Figs. 2 and 3, solely, the RQD value does not enable to estimate realistically the uniaxial compressive strength of rock masses $\left(\sigma_{\mathrm{cm}}\right)$. To predict more reliable $\sigma_{\mathrm{cm}}$ values the RQD value should be combined with joint inclination, and the strength along the critical/sliding joint.

- Ignoring the size of underground excavation and the time effect on the rock mass strength can raise serious errors. Hence, sound empirical/analytical methods based on comprehensive in situ measurements are urgently required in rock engineering. In other words, apart from the safety considerations, our fundamental aim is that the underground structures (mines, tunnels, gas stores, powerhouses etc.) should be constructed to last longer, to minimize maintenance/repair costs and hence life cycle costs.

Acknowledgments The findings were extracted from the study on the rock mass and strength, supported by the Yap1 Merkezi Inc. Istanbul/Turkiye. The authors are obliged to the Yap1 Merkezi R\&D Inc. Board, for permission to publish this discussion. The authors are also thankful to Prof. Dr. Nuh BILGIN of ITU Mining Eng. Dept., Istanbul and Prof. Dr. Giovanni BARLA of Politecnico di Torino, Dept. of Struc. and Geotech. Eng. for their academic interests and fruitful comments. The findings/comments expressed in this paper are those of the authors and not necessarily of the Yapı Merkezi to which they belong.

\section{References}

Alber M (2000) Advance rates of hard rock TBMs and their effects on project economics. Tunn Undergr Space Technol 15(1):55-64

Amusin B (1998) Ground control and design of deep mine openings. Int J Rock Mech Min Sci 35(89):4-5

Arıoglu E (1995) Optimum support of development roadways. In: Danuta Krzyszton (ed) Geomechanical criteria for underground coal mines. Central Mining Institute, Katowice, pp 185-240

Arıoğlu E, Arıŏglu B, Girgin C (1999) Stability evaluation and design of tunnel openings in brittle-massive rock masses, Turkey. In:
Third international symposium on sprayed concrete modern use of wet mix sprayed concrete for underground support, 26-29 September, Norway, pp 28-38

Barton N (2007) Rock mass characterization for excavation in mining and civil engineering. In: Mark C, Pakalnis R, Tunchman RJ (eds) Proceeding of the international workshop on rock mass classification in underground mining. IC 9498 Information Circular, Department of Health and Human Services, Pittsburgh, pp 3-13

Birön C, Arığ lu E (1983) Design of supports in mines. John Wiley \& Sons, New York, p 248

Goel RK, Jethwa JL, Paithankar AG (1995) Correlation between Barton's Q and Bieniawski's RMR - a new approach. Int J Rock Mech Min 33(2):179-181

Hoek E, Guevara R (2009) Overcoming squeezing in the YacambúQuibor tunnel, Venezuela. Rock Mech Rock Eng 42(2):389-418

Hoek E, Carranza-Torres C, Corkum B (2002) Hoek-Brown failure criterion-2002 edition. In: Proceedings of 5th North American rock mechanical symposium and 17th Tunneling Association of Canada conference: NARMS-TAC 2002. Mining Innovation and Technology, Toronto, pp 267-273

Palmström A (1995) RMi—a rock mass characterization system for rock engineering purposes. $\mathrm{PhD}$ thesis, University of Oslo, Norway

Palmström A (1996) Characterizing rock masses by the RMi for use in practical rock engineering. Tunn Undergr Space Technol 11(2):175-188

Palmström A, Stille H (2010) Rock Engineering. Thomas Telford, London, p 408

Priest SD, Hudson JA (1976) Discontinuity spacing in rock. Int J Rock Mech Min 13:135-148

Ramamurthy T (1993) Strength and modulus response of anisotropic rocks, chap 13. In: Comprehensive rock engineering, vol I. Pergamon Press, Oxford, pp 313-329

Ramamurthy T (2001) Shear strength response of some geological materials in triaxial compression. Int $\mathrm{J}$ Rock Mech Min 38:683-697

Ramamurthy T, Arora VK (1994) Strength predictions for jointed rocks in confined and unconfined states. Int J Rock Mech Min Sci Geomech Abstr 31(1):9-22

Singh B, Goel RK (2006) Tunnelling in weak rocks. Elseiver, London

Unrug KF (1983) Longwall support requirements. J Min Metals Fuels 334-344

Yoshinaka Y, Osada M, Park H, Sasaki T, Sasaki K (2008) Practical determination of mechanical design parameters of intact rock considering scale effect. Eng Geol 96:173-186

Zhang L (2010) Estimating the strength of jointed rock masses. Rock Mech Rock Eng 43:391-402 